\title{
POR UMA ANÁLISE ECONÔMICA DO DIREITO AO ESQUECIMENTO: A FÓRMULA DO DIREITO AO ESQUECIMENTO
}

\author{
Antonio José Maristrello Porto ${ }^{1}$ \\ Paulo Fernando de Mello Franco ${ }^{2}$
}

\section{Resumo:}

Uma vez inserida na Internet, a informação se eterniza e se replica a tal ponto que, com espantosa velocidade, pode causar danos extrapatrimoniais (e patrimoniais) irreversíveis. Surge, nesse contexto, o direito ao esquecimento como o mecanismo jurídico idôneo para proteger pessoas públicas e privadas (e físicas e jurídicas). A grande questão é: quando o direito de ser esquecido deverá preponderar sobre as liberdades comunicativas? O artigo se baseia na crença de que é possível sintetizar uma fórmula que sugira ao Judiciário se e quando deve ser reconhecida (ou repelida) a juridicidade do direito ao esquecimento.

Palavras-chave: Direito ao Esquecimento; Direitos da Personalidade; Liberdades Comunicativas; Análise Econômica do Direito

\section{ECONOMIC ANALYSIS OF LAW AND RIGHT TO BE FORGOTTEN: THE RTBF FORMULA}

\begin{abstract}
:
The Hyperinformation society experiences the Big Data Era. However, once inserted on the Internet, informations eternalize and replicate themselves and, with amazing speed, this phenomenon can cause irreversible extrapatrimonial (or even patrimonial) damages. Emerges, in this context, the right to be forgotten as Law mechanism to protect private and public persons. But the question is: when should the right to be forgotten surpass freedom of expression? The paper will be based in a belief that it is possible to synthesize a formula that leads the Judiciary to the (in)application of the RTBF.
\end{abstract}

Keywords: Right to be Forgotten; Personality Rights; Communicative Freedoms; Economic Analysis of Law

\footnotetext{
${ }^{1}$ Doutor e Mestre em Direito pela University of Illinois: Urbana - Champaign. Professor do Mestrado em Direito da Regulação e da Graduação da Fundação Getulio Vargas - FGV Direito Rio. Coordenador do Centro de Pesquisa em Direito e Economia (CPDE) da Fundação Getulio Vargas - FGV Direito Rio. E-mail: antonio.maristrello@fgv.br.

${ }^{2}$ Doutor em Direito pela Universidade Federal Fluminense (UFF) com estágio doutoral na Universidade de Vigo (UVIGO). Mestre em Direito pela Universidade Federal do Estado do Rio de Janeiro (UNIRIO). Pós-Graduado em Direito Público pela UCAM - Centro. Pesquisador do Centro de Pesquisa em Direito e Economia (CPDE) da Fundação Getulio Vargas - FGV Direito Rio. Professor de Direito Civil e Análise Econômica do Direito dos Cursos de Graduação e de Pós-Graduação da Fundação Getulio Vargas - FGV Direito Rio. E-mail: paulo.mello@fgv.br.
} 


\section{INTRODUÇÃO}

O direito ao esquecimento, enquanto termo multívoco que é, pode corresponder a inúmeros fenômenos.

O direito ao esquecimento pode se apresentar, a nosso ver, como: 1) o direito de deletar publicações; 2) o direito de impedir que alguma informação seja divulgada; 3) o direito de retificar dados; 4) o direito de requerer retratação ou errata; 5) o direito de pleitear, ainda que a posteriori, indenização (por dano direto ou mesmo reflexo ou em ricochete); 6) o direito à desindexação (deslistamento ou desreferenciação) de resultados de busca; 7) o direito de deixar toda e qualquer pretensão para lá (let it be) e, até mesmo; 8) o contradireito de não ser esquecido, como uma espécie de devoir de mémoir.

É isso o que, em nossa minha visão, o direito ao esquecimento pode significar.

O artigo parte do pressuposto de que é possível sintetizar uma fórmula que conduza o Poder Judiciário à (in)aplicação do direito ao esquecimento. A ideia é que, com isto, consigamos dizer, com o necessário rigor metodológico, se e quando deve ser conferida juridicidade ao dever de esquecer. Nossa pretensão é a de equacionar uma solução que seja, a um só tempo, exequível e compreensível ${ }^{1}$, justa e eficiente.

\section{UMA FÓRMULA PARA APLICAR O DIREITO AO ESQUECIMENTO}

Nossa proposta de fórmula se sustenta em uma premissa inafastável: quão maiores os níveis de relevância da informação; menores serão os benefícios advindos do cerceamento desse conteúdo. Noutro dizer, a normatividade do direito ao esquecimento dependerá, prima facie, de sua eficiência.

\footnotetext{
${ }^{1}$ Digo isso à luz das quatro fórmulas sobre as liberdades de expressão oferecidas por Posner como comentários críticos à decisão do caso Schenck vs. EUA (sobre o qual já falamos) que, a despeito das belíssimas explicações do autor, me parecem de difícil aplicação e entendimento pelo grande público. Quanto às fórmulas que mencionei, v. POSNER, Richard A.. Fronteiras da teoria do direito. Tradução: EVANDRO ERREIRA E Silva; Jefferson Luiz Camargo; Paulo Salles e Pedro Sette-Câmara. São Paulo: Editora WMF Martins Fontes, 2011, p. 54-56.
} 
O que queremos dizer é que, como uma relação de custo-benefício (cost benefit ${ }^{2}$ ), o direito ao esquecimento tenderá a ser eficiente se e somente se as vantagens auferíveis de sua juridicidade - e, pois, de sua aplicação - superarem os graus de importância da veiculação de determinada notícia ou reportagem, os quais serão enxergados aqui como custos.

As variáveis da "relevância da informação"- i.e., custo - e do "benefício da retirada dessa informação"- ou seja, o benefício propriamente dito - são, portanto, inversamente proporcionais, pelo que podem ser assim ilustradas:

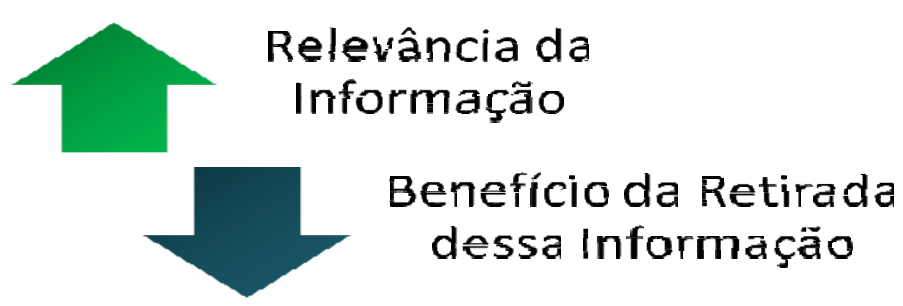

Elaboração própria dos autores

Isso, porém, não exaure a questão. Será preciso que antes tornemos palpável o binômio relevância-benefício, o que faremos a partir da definição de uma escala de interdependência entre estes vetores que, de 1 (um) a 5 (cinco), demonstrarão relações de correspondência entre a relevância da informação e o provável benefício extraível da retirada desta informação dos meios de comunicação.

\subsection{O Critério de Relevância-Benefício das Informações}

Deve-se olhar primeiro para a relevância da informação. O grau de benefício social que se auferirá com a exclusão desta informação será obtido como consequência desta (i)rrelevância - i.e., em linguagem econométrica, o quantum de benefício do apagamento de informações é uma variável dependente ${ }^{3}$ da relevância destas informações -, o que assim se esquematiza:

\footnotetext{
2 "Porém, no contexto da abordagem à liberdade de expressão fundada nos custos e beneficios, as medidas do legislativo (ou de qualquer outro poder do Estado) que restrinjam o discurso só devem ser permitidas quando se puder demonstrar, com certo grau de certeza, que os benefícios da restrição excedem os custos" cf. POSNER, Richard A.. Fronteiras da teoria do direito. Tradução: EVANDRO ERREIRA E Silva; Jefferson Luiz Camargo; Paulo Salles e Pedro Sette-Câmara. São Paulo: Editora WMF Martins Fontes, 2011, p. 60.

${ }^{3}$ Em econometria, as variáveis podem ser dependentes ou independentes. As variáveis dependentes são aquelas cujo valor depende, com o perdão da redundância, da manipulação de outra(s) variável(eis). Por sua vez, as variáveis independentes correspondem às variáveis manipuladas pela pesquisa, em relação as
} 
quais é analisada sua influência sobre as demais variáveis, ou seja, como estas podem influenciar aquelas. $V$., a esse respeito, BISQUERRA, R.; SARRIERA, J. C.; MARTÍNEZ, F. Introdução à estatística: enfoque informático com o pacote estatístico SPSS. Tradução de Fátima Murad. Porto Alegre: Artmed, 2004.

\section{Escala do Binômio Relevância-Benefício}

\begin{tabular}{|c|c|c|}
\hline Relevância da Informação & & Benefício da Retirada dessa Informação \\
\hline 5 & $\rightarrow$ & 1 \\
\hline 4 & $\rightarrow$ & 2 \\
\hline 3 & $\rightarrow$ & 3 \\
\hline 2 & $\rightarrow$ & 4 \\
\hline 1 & $\rightarrow$ & 5 \\
\hline
\end{tabular}

Elaboração própria dos autores

Apenas para exemplificar o que quisemos mostrar com o gráfico, imaginemos uma informação classificada em um nível 5 (cinco) de relevância: a retirada deste conteúdo tenderia a gerar um proveito social de grau 1 (um), o que indicaria que a aplicação do direito ao esquecimento não seria, aparentemente, recomendável neste caso. Isto porque, em outras palavras, o custo social do apagamento de uma informação muito relevante é expressivamente mais alto do que o benefício que porventura se obteria com a sua supressão.

Por outro lado, a retirada de uma informação de baixa importância, classificada como sendo de nível 2 (dois) de relevância, por exemplo, produziria um benefício social de grau 4 (quatro), o que indicaria que, nesta outra hipótese, a imposição do dever de esquecer tenderia a ser eficiente.

\subsection{Uma primeira tentativa de fórmula do direito ao esquecimento}

Assim, de modo esquemático, seria razoável afirmar, à luz de uma Análise também Econômica do Direito, que o direito ao esquecimento deveria ser aplicado sempre que:

$$
\begin{aligned}
& \boldsymbol{B}>\boldsymbol{R} ; \\
& \text { donde: } \\
& R=\text { Relevância da Informação e; }
\end{aligned}
$$


$B=$ Benefício da Retirada dessa informação.

Isso, porém, ainda não resolveria o dilema do direito ao esquecimento. Essa simples equação seria insuficiente para sanar uma ponderação de valores que envolvesse a manutenção ou retirada de determinado um conteúdo que, v.g., possuísse grau 3 (três) de classificação relevância. Afinal, o benefício correspondente à exclusão seria, à luz da escala que aqui propusemos, igualmente 3 (três).

Superaríamos essa incompletude se contemplássemos na fórmula, além da relevância da informação $(R)$ e do benefício da retirada dessa informação $(B)$, um fator de depreciação de relevância - que chamaremos de $x$ - que poderia ser ou não ser significativo para o nosso cálculo. Esse fator $x$ (de depreciação de relevância) deveria ser igual a 0 se o conteúdo da informação que se pretende esquecer tivesse propósito primordialmente informativo ou; deveria ser igual a 1 (um) se, por outro lado, o principal objetivo da notícia ou reportagem fosse um intuito lucrativo, especulativo ou malicioso, que poderia estar disfarçado de uma suposta liberdade comunicativa de informação ou de expressão. Em outras palavras, sendo predominante o intuito informativo de um determinado conteúdo, inexistirá depreciação da relevância desta informação, pelo que $x$ será igual a 0 (zero); por outro lado, ausente a predominância informativa, o fator $x$ de depreciação será igual a 1.

\subsubsection{Mais uma tentativa de fórmula do direito ao esquecimento}

Desse modo, com a adição do fator $x$ na equação, o conflito de interesses aqui discutido poderia ser assim expresso:

$$
\begin{aligned}
& \boldsymbol{B}>\boldsymbol{R}-\boldsymbol{x} ; \\
& \text { donde: } \\
& R=\text { Relevância da Informação; } \\
& B=\text { Benefício da Retirada dessa informação e; } \\
& x=\text { Fator de Depreciação da Relevância, podendo este } \\
& \text { ser igual a } 0 \text { (se o propósito informativo é primário) ou } \\
& 1 \text { (se o propósito informativo é secundário). }
\end{aligned}
$$

A inclusão do fator $x$ no cômputo dessa equação, a nosso ver, além de 
solucionar os casos que envolvam informações de relevância - e de benefício - de nível 3 (três), corroboraria a tese de que nem todos os conflitos sobre o direito ao esquecimento versam sobre direitos existenciais versus direitos igualmente existenciais. Afinal, se é possível que percebamos que há situações nas quais as informações têm propósitos mais lucrativos do que propriamente informativos, é porque, por vezes - e com certa frequência -, as contendas de direito ao esquecimento ilustram uma ponderação de interesses entre os direitos existenciais dos que pleiteiam o dever de esquecer versus o intuito patrimonial dos que, a pretexto de informar, se valeram do poder-dever que têm para atingir pretensões primordialmente econômicas.

A variável $x$ da equação do esquecimento visa a aferir o newsworthy, i.e., o mérito da notícia ou o mérito da informação em sentido amplo: se o conteúdo do que se compartilhou nos meios de comunicação não ilustrar um propósito (mérito) preponderantemente informativo, o fator $x$ da equação do esquecimento depreciará a relevância desta informação $(R-x)$. Isso porque, despida de valor como notícia (GARCIA, 2002, p. 234), ou seja, not newsworthy, a informação não contribui para a formação da opinião pública (marketplace of ideas) e, pois, não merece ser vista como concretizadora de um dever de informar, tampouco de um suposto direito à informação - os quais, disfarçados, apenas serviram de argumento para encobrir interesses secundários dos meios de comunicação.

A inserção do fator $x$ no cálculo da fórmula do direito ao esquecimento é determinante para que se possa valorar corretamente em que situações o dever de esquecer deve ou não prevalecer. Por exemplo, se se tratar de informação cujo escopo é, de fato, informar, situações de relevância 3 (três) e de benefício 3 (três) terão uma solução que reconhecerá, na prática, a posição preferencial que, em regra, as liberdades comunicativas têm. Assim, em se tratando de conteúdo cujo interesse primário é o direito à informação (ou à liberdade de expressão e crítica),

$$
\begin{aligned}
& x=0 \text { (se o propósito informativo é primário); } \\
& \text { donde: } \\
& B>R-x ; \\
& 3>3-0 ; \\
& \text { logo: }
\end{aligned}
$$




$$
3=3,
$$

pelo que, diante da igualdade de graus de relevância e de benefício, o direito ao esquecimento tenderia a não ser aplicado.

Por outro lado, o mesmo não se poderia dizer em relação a hipóteses 3-3 (três-três) de relevância-benefício que contivessem flagrante abuso do direito de informar - i.e., situações nas quais o conteúdo informativo se evidenciaria secundário: a conclusão, nestes casos, seria diametralmente oposta. É que, diante do predomínio do caráter econômico da informação,

$$
\begin{aligned}
& x=1 \text { (se o propósito informativo é secundário); } \\
& \text { donde: } \\
& B>R-x ; \\
& \begin{array}{l}
3>3-1 ; \\
\log :
\end{array} \\
& 3>2 .
\end{aligned}
$$

de modo que, de acordo com o que até aqui expusemos, o direito ao esquecimento deveria prevalecer (em razão de $B$ ser maior do que $R$ ).

Em hipóteses 3-3 (três-três) de relevância-interesse como essa, as liberdades comunicativas não manteriam sua posição preferencial por conta da natureza subsidiária do conteúdo informativo veiculado. Aliás, pelo contrário, a posição preferencial seria ocupada, isto sim, pelos direitos da personalidade que estivessem em jogo, os quais, porque existenciais, tenderiam a prevalecer sobre os de índole patrimonial. Até porque, sempre que digladiarem direitos existenciais versus direitos patrimoniais, concordamos que aqueles (existenciais) têm ao menos uma posição preferencial de primazia sobre estes (patrimoniais) ${ }^{4}$.Finito? Parece-nos ainda imperfeita a fórmula do esquecimento.

\subsubsection{Finalmente o esboço de fórmula do direito ao esquecimento}

Devemos incluir mais uma última variável em nossa equação. Sugerimos a inserção do que passamos a denominar de índice de falsidade de uma determinada 
informação, a qual optamos por chamar de $y$. Com a inclusão da variável $y$, pretendemos tornar possível o cálculo da relevância de uma informação em situações nas quais as liberdades comunicativas se prestam a distorcer a realidade e a propagar mentiras indiscutíveis, a exemplo das fake news. Haverá casos em que as informações aparentarão ter - segundo o critério de relevância-benefício aqui proposto - um elevado grau de importância, mas que, por conta do conteúdo notadamente inverídico, não devem prevalecer sobre um eventual pedido de direito ao esquecimento.

4"[...] as situações jurídicas subjetivas existenciais prevalecem sobre as patrimoniais em hipótese de conflito, pois naquelas, em primeiro plano, se exprime o ser e o agir da pessoa humana". Cf. VENCELAU, Rose Melo. Autonomia privada e dignidade humana. Rio de Janeiro: Renovar, 2009, p. 9.

Suponhamos que um jornal de grande circulação decida publicar uma reportagem que se disponha a relatar um suposto fato ocorrido no passado político de um determinado parlamentar recém-eleito: por apresentarem - tanto o político quanto o conteúdo veiculado - natureza pública, a informação divulgada aparentaria ter um alto nível de relevância, pelo que, prima facie, um pedido de direito ao esquecimento tenderia a ser afastado. Ocorre que, se essa notícia é nada mais do que um embuste i.e., existe prova irrefutável em sentido contrário apta a comprovar que a reportagem desfigurou a realidade -, a relevância da informação (que é tão-só aparente) não deve preponderar sobre o benefício que se obterá - tanto por parte da vítima, quanto pela sociedade em geral - com a exclusão ou bloqueio desta pseudoinformação.

Notícias, reportagens ou programações de TV e de Internet que contenham informações que comprovadamente não condigam com a verdade - fake news em geral - devem, sim, ser esquecidas. E, para expressarmos essa afirmação na fórmula do esquecimento, incluímos o fator y na equação, o qual valerá 0 (zero) ou 1 (um). A variável y será igual a 0 (zero) se a informação em análise for indiscutivelmente falsa; por outro lado, y será igual a 1 (um) se a informação que se pretende esquecer for verdadeira ou, ainda que não reflita necessariamente a verdade, que ao menos paire sobre ela uma dúvida razoável quanto à sua veracidade.

Em relação a esse último aspecto (da dúvida razoável quanto à veracidade da informação ou, mais especificamente, de sua verossimilhança), não será qualquer suspeita que autorizará que enquadremos essa informação em um fator $y$ igual a 1 (um). Apenas e tão somente dúvidas razoáveis, sobre as quais efetivamente haja indícios de 
fidedignidade - i.e., como uma espécie de fumus boni notitia - é que merecerão um índice $y$ maior do que 0 (zero).

Para que haja dúvidas razoáveis sobre algo ou sobre alguém, é preciso que, quando do tratamento das informações que compartilham ou que pretendem compartilhar, os meios de comunicação tenham precaução - precaução esta que, convenhamos, nada mais é do que a tradução econômica dos deveres jurídicos de diligência e de cuidado que são anexos à boa-fé objetiva ${ }^{5}$. Por conseguinte, uma vez que os direitos (in casu, o direito de informar e o direito à informação) pressupõem deveres,

\footnotetext{
${ }^{5} \mathrm{O}$ que queremos dizer com a variável y é que se impõe um inafastável dever de diligência - de zelo, de esmero, de cautela ou de cuidado - por parte dos meios de comunicação que, indiscutivelmente, têm de exaurir a checagem das fontes e dos conteúdos do que se propuserem a divulgar. É nesse ponto que se insere o que chamamos de dúvida razoável exigível das liberdades comunicativas, apta a fazer com que y seja igual a 1 (um).
}

a inobservância dos custos de precaução imponíveis aos meios de comunicação precisa se traduzir em responsabilidade civil - i.e., no dever de indenizar -, a fim de que se estimule, pela via do Direito, a formatação de um dever fundamental de informar bem o qual apenas poderá ser atingido se e somente se os meios de comunicação forem adequadamente incentivados a investir em precaução informativa.

À luz de uma Análise também Econômica do Direito, o dever de cautela necessariamente se imporia aos meios de comunicação porque os custos desta precaução (C) seriam certamente menores do que o dano esperado (DE) que poderia vir a ser causado ela publicação irresponsável de notícias e reportagens sem a devida apuração, o qual seria obtido a partir da multiplicação do dano (d) propriamente dito pela probabilidade (p) de que este dano efetivamente ocorresse. Digo isso porque, tendo em vista que os danos provocados pelos meios de comunicação têm, especialmente quando publicados na Internet, exponencial magnitude e elevada probabilidade de acontecer, é eficiente - e mais do que razoável - compelir que os veículos de informação invistam significativamente em precaução. Para desenvolver este raciocínio - segundo o qual os custos de precaução são estimados de acordo com o DE $(d$. p) -, me inspiro na denominada Fórmula de Hand $^{6}$ que, para uma Análise também Econômica do Direito, se presta a calcular, na minha visão, o quanto de cautela se pode exigir de 
${ }^{6}$ A racionalidade da Fórmula de Hand nos remete ao caso USA vs. Carrol Towing Company, o qual foi julgado por Learned Hand, juiz que passou a intitular a Fórmula. A controvérsia versava sobre um barco transportador (Anna C), que pertencia à Conners Company, que, carregado com farinha de trigo adquirida pelo governo dos EUA, acabou afundando - juntamente com a sua carga - em razão do rompimento das cordas que prendiam a embarcação ao piér da baía de Nova Iorque, o que gerou posterior colisão com outro barco. A proprietária do barco Anna C, que não estava tripulado no momento do afundamento, argumentou que as cordas da embarcação - que estava comprovadamente bem amarrada - apenas e tão somente se soltaram por conta da movimentação brusca de um outro navio (Carrol), que se encontrava no mesmo local, de responsabilidade da Carroll Towing Company, ré do processo. De quem seria a culpa pelos prejuízos causados? Do terceiro que, em razão da conduta das movimentações bruscas e do nexo causal que ocasionou o rompimento das cordas do Anna C? Ou da própria vítima, que foi negligente ao não deixar tripulação alguma para supervisionar o barco caso houvesse problemas? Para Hand e sua Fórmula, os custos de precaução (C) devem ser sopesados com a magnitude dos danos que podem vir a ser causados (d) vezes a probabilidade de que estes possam acontecer (p). Assim, tendo em vista que os custos de precaução eram consideravelmente baixos quando comparados com o dano esperado em razão de um eventual acidente, era dever imponível à vítima - que também deve investir para evitar que o dano aconteça - ter alocado um funcionário para tomar conta da embarcação. A ausência desse investimento em cuidado, cujo custo era notadamente menor do que o $d . p$ de uma eventual colisão ou afundamento, faz com que se perceba que a vítima concorreu culposamente (por negligência) para a ocorrência do dano. Assim, usando a Fórmula que posteriormente viria a ser chamada pelo seu nome, o juiz Hand reconheceu ter havido culpa por parte da Carroll Towing Company, mas a abrandou em razão de a Conners Company não ter investido o suficiente em precaução, o que era plenamente exigível dela. $O$ fato é que o paradigmático caso poderia servir, especialmente no Brasil, para lançar luzes sobre como calcular a negligência de alguém, especialmente da vítima, a fim de que se possa quantificar, sem a insegurança do subjetivismo judicial, o quanto se pode exigir da vítima à título de dever de mitigar o próprio prejuízo (o duty to mitigate the loss, como figura parcelar da boa-fé objetiva), o que, infelizmente, não encontra parâmetros bem definidos no judiciário brasileiro.

um potencial ofensor. Para Hand, uma conduta é considerada culposa - e, pois, passível de reprimenda judicial - se o investimento em precaução $(C)$ do responsável por esta conduta é menor do que o montante do dano esperado (DE). Em outras palavras, para Hand, haverá culpa sempre que $C<d . p^{7}$.

Munidos desse raciocínio, a Fórmula de Hand poderia sugerir que inexistirá dúvida razoável em favor de informações veiculadas cujo $C$ de precaução dos meios de comunicação seja menor do que o $D E(d \cdot p)$. Em outras palavras, quando os investimentos em precaução informativa forem insuficientes - i.e., sendo $C<d$. p - a variável y da fórmula do esquecimento será igual a 0 (zero). A inserção - no Direito do cálculo - da Economia - dos níveis de diligência que se impõem aos causadores de danos em geral tende a (re)dimensionar o hiato entre poderes e deveres dos meios de comunicação que, não raro, são tidos como infensos à quaisquer espécies de controle ou regulação. Equacionar o nível ótimo de precaução e calcular o quanto se pode exigir de cautela por parte dos meios de comunicação nos conduziria, a nosso ver, à um duplo benefício: por um lado, reduziria o grau de incerteza que paira sobre o conceito de culpa stricto sensu - principalmente em relação à negligência - e; por outro, criaria incentivos para que os meios de comunicação investissem acima do nível ótimo de precaução - 
afinal, sendo calculável o ponto ótimo, valeria a pena investir mais em cautela porque a comprovação destes investimentos tenderia a gerar um quantum indenizatório menor.

Enfim, exprimidas as considerações pertinentes, o elemento $y$ seria inserido na equação do esquecimento da seguinte maneira:

$$
\begin{aligned}
& \boldsymbol{B}>(\boldsymbol{R}-\boldsymbol{x}) \cdot \boldsymbol{y} ; \\
& \text { donde: } \\
& R=\text { Relevância da Informação; } \\
& B=\text { Benefício da Retirada dessa informação; } \\
& x=\text { Fator de Depreciação da Relevância, podendo este } \\
& \text { ser igual a O (se o propósito informativo é primário) ou } \\
& l \text { (se o propósito informativo é secundário) e; }
\end{aligned}
$$

\footnotetext{
${ }^{7}$ Esclareço que embora a regra de Hand se disponha a aferir culpa, ela também se presta a auxiliar a racionalidade jurídica da responsabilidade civil objetiva. Explico. A fórmula de Hand não calcula apenas a precaução do ofensor: ela pode ser utilizada para aferir os níveis de precaução das vítimas. Assim, situações de culpa concorrente ou de culpa exclusiva da vítima poderiam ser assim enquadradas a partir da equação $C<d . p$. Gráfico traduzido pode ser conferido em PORTO, Antônio José Maristrello; FRANCO, Paulo Fernando. Uma Análise Também Econômica do Direito de Propriedade. Economic Analysis of Law Review. vol.7. n¹. p. 207-232. jan-jun 2016.

$y=$ Índice de Verossimilhança da Informação, podendo este ser igual a 0 (se a informação é comprovadamente falsa) ou 1 (se a informação é verdadeira ou há dúvida razoável quanto a sua veracidade).
}

A inclusão da variável y na fórmula do direito ao esquecimento permite que afirmemos que, uma vez que qualquer número multiplicado por 0 (zero) é igual a 0 (zero), o apagamento de informações falsas e quaisquer espécies de fake news - cujo y é igual a 0 (zero) - será sempre eficiente porque $B$ - que varia entre 1 (um) e 5 (cinco) será necessariamente maior do que 0 (zero). O índice y servirá, portanto, como um detector da ausência de fumus boni notitia, i.e., da inexistência de indícios de que houve comprometimento com os custos exigíveis de precaução por parte dos meios de comunicação: em não havendo fumus, $y$ de uma notícia ou reportagem publicada sem a devida cautela será igual a 0 (zero), de modo que o direito ao esquecimento deverá prevalecer.

Por fim, concluído o desenho da fórmula do direito ao esquecimento, resta 
isolarmos o lado direito da equação para facilitar a compreensão da fórmula, pelo que substituiremos o fragmento

$$
(R-x) \cdot y
$$

por uma incógnita que escolhemos chamar de $\alpha$ :

$$
\alpha=(R-x) \cdot y
$$

Agora sim, finalmente, a fórmula do direito ao esquecimento nos parece íntegra e plenamente aplicável:

$$
\begin{aligned}
& \boldsymbol{B}>\boldsymbol{\alpha} ; \\
& \text { donde: } \\
& \alpha=(R-x) \cdot y ; \\
& \text { Logo: }
\end{aligned}
$$

Se B $>\alpha$;

Aplica-se o direito ao esquecimento.

Se $B<\alpha$;

Não se aplica o direito ao esquecimento.

Se $B=\alpha$;

Aplica-se a regra da ponderação de princípios ou de interesses.

Concluída a fórmula do direito ao esquecimento, passo a formatar critérios para alocar uma determinada informação - a respeito da qual se discute a (in)aplicação do dever de esquecer - em um dos 5 (cinco) níveis de relevância que acima propusemos.

\section{A ESTRUTURAÇÃO DOS 5 (CINCO) NÍVEIS DE RELEVÂNCIA DA INFORMAÇÃO}

Como dissemos anteriormente, a variável dependente dos graus de benefício da retirada de informações - ou, em outras palavras, os níveis do que se auferirá de vantagem com a aplicação do direito ao esquecimento - será encontrada após a subsunção da informação que se quer esquecer em algum dos 5 (cinco) estratos de 
relevância que propus. Vê-se primeiro a relevância da informação e; depois, o coeficiente do benefício de sua retirada - que poderá ser elevado ou diminuto, a depender dos índices de relevância dessa informação. Mas, alguém poderia questionar: como nivelar uma informação em grau de relevância 1 (um), 2 (dois), 3 (três), 4 (quatro) ou 5 (cinco)? Diríamos, em resposta, que será preciso entabular parâmetros para que se insira uma determinada informação em algum desses 5 (cinco) graus de relevância informativa propostos, nos moldes do que sugerimos a seguir:

\section{Níveis de Relevância da Informação}

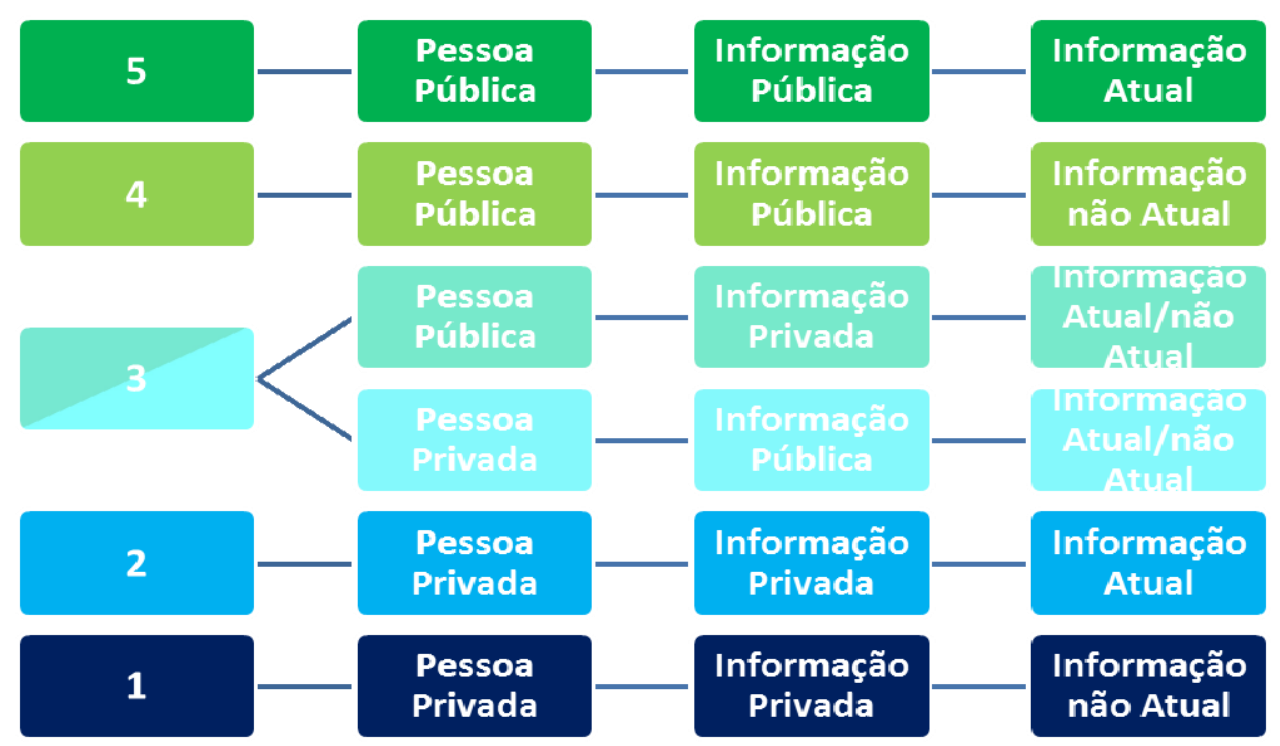

Elaboração própria dos autores

São esses os critérios que entendemos adequados para conceber os 5 (cinco) diferentes graus de relevância que uma informação pode ter. Algumas explicações, porém, nos parecem pertinentes.

Primo, inexiste grau 0 (zero) ou negativo $(-1, v . g$.) de relevância porque as informações têm valor econômico e, por mais que aparentemente sejam desinteressantes, interessarão, sempre, para alguém - nem que seja, pelo menos, para a própria pessoa que é retratada ou noticiada pelos meios de comunicação.

Secundo, o maior grau que uma informação de uma pessoa privada pode atingir é 3 (três) e o menor grau que uma informação de uma pessoa pública pode atingir também é 3 (três).

Logo, tertio, informações de pessoas públicas tendem a ser mais relevantes que as de pessoas privadas. Portanto, o aspecto subjetivo da informação - relacionado à 
pessoa pública ou privada mencionada pelos meios de comunicação - tende a ser determinante para fins de (in)aplicação do direito ao esquecimento.

Quarto, informações de relevância de níveis 4 (quatro) e 5 (cinco) experimentarão posição preferencial das liberdades comunicativas, ao passo que informações de relevância de níveis 2 (dois) e 1 (um) experimentarão posição preferencial da intimidade, privacidade e honra.

Quinto, informações de relevância 3 (três) não experimentarão posição preferencial das liberdades de expressão, tampouco dos direitos da personalidade. Nestas situações, o que talvez sugira que a ponderação deva se inclinar para um ou para outro lado seja a atualidade ou não dessas informações - o que impactará no fator de depreciação de sua relevância.

Sexto, esses graus de atualidade da informação devem ser necessariamente aferidos no caso concreto. É que, a nosso sentir, não há como estipular a priori a variável da atualidade em números e in abstracto porque haverá informações que, mesmo antigas, ainda assim serão relevantes. É o caso, e.g., de crimes cometidos há muitos anos por algum político - desde que, claro, tenham sido de fato cometidos, a fim de que não se confundam com fake news. O que definirá se informações como estas têm de ser mantidas ou esquecidas será o nível de malice - ou seja, um propósito manifestamente especulativo ou predatório e em dissonância com o princípio da boa-fé - da publicação e não, especificamente nestes casos, a contemporaneidade do conteúdo.

Septimo, a equação do direito ao esquecimento não se presta a solucionar conflitos que envolvam obras ficcionais ou expressões artísticas, como shows, peças de teatro, novelas e filmes, v.g.. A fórmula se restringe às liberdades comunicativas que se dispõem a difundir informações - reportagens de revista, matérias de jornal, documentários de TVe postagens em blogs ou Redes, e.g.. Por quê? Porque a fórmula do esquecimento lida com informações sobre pessoas públicas ou pessoas privadas e as personagens de obras ficcionais ou artísticas não são pessoas. São, com o perdão da redundância, personagens - e, portanto, destituídos de dignidade ou integridade psicofísica a ser protegida.

\subsubsection{A $1^{\text {a }}$ Regra (Critério Subjetivo ou da Pessoa) de Definição dos Níveis de Relevância da Informação: Informações sobre pessoas públicas tendem a ser mais}




\section{relevantes do que informações sobre pessoas privadas}

A primeira distinção que se deve fazer, para que definamos o grau de relevância de uma informação, é em relação à pessoa noticiada ou reportada, i.e., quanto aos aspectos subjetivos do que se comunica: trata-se de informação sobre pessoa pública ou sobre pessoa privada? Isso nos parece relevante porque, se se tratar de informação que diga respeito à uma pessoa pública, o conteúdo da reportagem ou da notícia tende a ser mais importante: ocupará, portanto, um dos níveis 3 (três), 4 (quatro) ou 5 (cinco) de relevância. Por outro lado, se se tratar de informação que verse sobre pessoa privada, o conteúdo informativo tende a ser menos relevante, pelo que ocupará algum dos níveis 1 (um), 2 (dois) ou 3 (três) de importância.

Dito isso, ainda caberia questionar: como definir se uma pessoa é pública ou privada? Em um primeiro momento, seriam considerados pessoas públicas os agentes políticos e os agentes públicos em geral $^{8}$ e, em especial, os servidores e empregados públicos, incluído nesse rol os ocupantes de cargos em comissão e aqueles que se subsumam ao conceito de pessoas politicamente expostas (PPE) ${ }^{9}$. Também seriam classificáveis como pessoas públicas os artistas em geral, cantores e cantoras, atores e

\footnotetext{
${ }^{8}$ Art. $2^{\circ}$, Lei $8.429 / 82$ (Lei de Improbidade Administrativa). Reputa-se agente público, para os efeitos desta lei, todo aquele que exerce, ainda que transitoriamente ou sem remuneração, por eleição, nomeação, designação, contratação ou qualquer outra forma de investidura ou vínculo, mandato, cargo, emprego ou função nas entidades mencionadas no artigo anterior.

${ }^{9}$ Nos termos do que definem a Lei $n^{\circ}$ 9.613/98 - com as alterações da Lei ${ }^{\circ} 12.683 / 12$ - que, dentre outras providências, criou o Conselho de Controle de Atividades Financeiras (COAF) e definiu algumas PPE; a Resolução n ${ }^{\circ}$ 16/2007 do COAF, que já tratava do assunto e experimentou, após o surgimento da Resolução no 29/2017 do mesmo COAF, expansões e exclusões em sua listagem de pessoas consideradas PPE.
}

atrizes, âncoras e repórteres de jornais televisionados, apresentadores de programas ao vivo, jogadores de futebol e demais esportistas e quaisquer outros indivíduos que, por opção, escolheram - após calcular o custo de oportunidade ${ }^{10}$ da exposição remunerada em trade off com o anonimato não rentável - ter constante aparição midiática, razão pela qual são mais suscetíveis a serem lembrados pelos meios de comunicação ${ }^{11}$. $\mathrm{O}$ custo de oportunidade de ser uma pessoa pública é equivalente à utilidade esperada ao optar pela não notoriedade. O verdadeiro custo de se expor nas mídias depende mais de quanto o indivíduo valoriza sua não exposição do que a quantidade de remuneração que se receberá por esta exposição. O restante das pessoas, i.e., aquelas sem qualquer habitualidade de exposição - especialmente remunerada, mas não exclusivamente ${ }^{12}-$ ou 
que sequer cogitam de que sua imagem - voz, atributo, retrato e nome - possa vir a ser veiculada nas mídias, deverão ser categorizadas como pessoas privadas - pelo que, a meu ver, também seriam considerados pessoas privadas os usuários de Redes Sociais que, embora deixem seus perfis abertos ${ }^{13}$, não têm expectativa - nem autorizaram ou consentiram que tal se desse - de que seus posts sejam pulverizados nos e pelos meios de comunicação, até mesmo pela ausência de finalidade econômica destas publicações.

\subsubsection{A $2^{\mathrm{a}}$ Regra (Critério do Objeto) de Definição dos Níveis de Relevância da Informação: Após olharmos para a pessoa, devemos olhar para a natureza da informação veiculada}

\footnotetext{
10 "Custo de oportunidade de um item é aquilo de que você abre mão para obtê-lo. Ao tomarem qualquer decisão, como a de frequentar a faculdade, por exemplo, os tomadores de decisões precisam estar cientes dos custos de oportunidade que acompanham cada ação possível. Atletas universitários que podem ganhar milhões se abandonarem os estudos e se dedicarem ao esporte profissional estão bem cientes de que, para eles, o custo de oportunidade de cursar a faculdade é muito elevado. Não é de surpreender que muitas vezes concluam que o benefício de estudar não compensa o custo de fazê-lo". MANKIW, N. Gregory. Princípios de Microeconomia. $5^{\mathrm{a}}$ Edição, Cengage Learning, 2009, p. 6.

${ }^{11} \mathrm{O}$ que incluiria como pessoas públicas ou publicamente expostas os digital influencers de Instagram, Twitter, Facebook e Youtube e demais netizens que, direta ou indiretamente, aufiram vantagens com seus posts patrocinados.

${ }^{12}$ Seria o caso, por exemplo, de um líder comunitário usualmente conceda entrevistas em programas de TV: a concessão de entrevistas, embora não seja remunerada, é capaz de criar no entrevistado a legítima expectativa de uma constante aparição nos meios de comunicação - desde que, claro, essas aparições constantes se deem em razão de reportagens que tenham a ver como os interesses da comunidade que é líder. Assim, a remuneração ou não da exposição, conquanto seja um critério que indicie a propensão à exposição, não é necessariamente determinante porque mesmo pessoas que não recebem qualquer quantia para aparecer na TV podem ter essa expectativa e, portanto, serem consideradas pessoas públicas.

${ }^{13} \mathrm{Ou}$ seja, perfis sem limitação de privacidade, cujo conteúdo pode ser visto por qualquer um que, não bloqueado, acesse estes perfis. $\mathrm{O}$ oposto dos perfis abertos seriam os perfis fechados, nos quais somente usuários escolhidos - ou por convite ou porque foram adicionados por quem publica - podem acessar o conteúdo destes perfis. É o que ocorre, por exemplo, no Facebook e no Instagram, que possibilitam que seus usuários definam as configurações de privacidade para permitir ou impedir que "estranhos", que não sejam seus amigos ou seguidores, acessem suas publicações.
}

Além dos aspectos subjetivos de uma informação, é indispensável discernir a natureza do conteúdo do que se dissemina nos e pelos meios de comunicação: trata-se de informação pública ou privada? Esse discrímen (de caráter objetivo) nos parece imprescindível porque é preciso que se diga que mesmo públicas têm informações privadas - informações estas que não devem ser divulgadas nos veículos de comunicação que, em última análise, se circunscreveriam ao compartilhamento de conteúdos de cunho notadamente público. Do mesmo modo, há informações que, embora concirnam à pessoas privadas, têm caráter notadamente público - o que, a 
contrario sensu, recomendaria que este tipo de conteúdo devesse ter maior publicidade do que teria uma informação de índole tão-só privada.

Tanto num caso quanto noutro, os aspectos subjetivos (ser pessoa pública ou ser pessoa privada) da informação não serão necessariamente determinantes para que se sugira sua manutenção ou seu apagamento dos meios de comunicação não virtuais. $\mathrm{O}$ que poderá preponderar será a natureza do conteúdo da informação, pelo que, se se tratar de informação pública - diga ela respeito à pessoa pública ou ainda que à pessoa privada -, a preservação das liberdades comunicativas tenderá a prevalecer. Ao revés, se se tratar de informação privada - referente tanto a pessoas públicas quanto privadas , o direito ao esquecimento tenderá a ser aplicado.

Em outras palavras, notícias ou reportagens sobre uma pessoa pública que contenham informações privadas sobre esta mesma pessoa tenderão a ter um grau menor de relevância informativa do que teria, por evidente, uma informação pública de uma pessoa pública. No mesmo sentido, apontamentos públicos de pessoas privadas tendem a ter maior relevância da informação do que matérias privadas sobre pessoas também privadas. Pelo exposto, conteúdos públicos sobre pessoas públicas tenderiam a ocupar um dos níveis 4 (quatro) ou 5 (cinco) de relevância da informação. A seu turno, informações privadas sobre pessoas privadas tenderiam a ocupar algum dos níveis 1 (um) ou 2 (dois) de importância informativa. E, de modo residual, seriam classificáveis no nível 3 (três) de relevância as informações de pessoas públicas ou privadas que fossem, respectivamente, privadas ou públicas. Concluímos, com isso, que a informação de pessoa privada mais relevante é aquela que contém conteúdo público e; que a informação de pessoa pública mais irrelevante ou menos relevante é aquela que contém conteúdo privado - ambas categorizadas como sendo de nível 3 (três) de relevância.

Por fim, uma última indagação merece ser respondida: como definir se uma informação é pública ou privada? Para nós, o conceito de informação pública exige o preenchimento de dois pressupostos cumulativos: não basta que uma informação seja de interesse coletivo; é preciso que esta informação seja, também, de relevância coletiva. Não merecerão exposição informações que, a despeito de gerarem interesse coletivo, não se mostrarem coletivamente relevantes. Por exemplo, por mais que algumas pessoas tenham interesse em saber que um cantor $\mathrm{Z}$ ou que uma atriz $\mathrm{W}$ comprou pão na padaria, a irrelevância desta informação tornaria impertinente o compartilhamento de tal 
"notícia" ou "reportagem". Aliás, em razão da ausência de relevância coletiva, a divulgação dessas “informações” sequer notícia ou reportagem seria ${ }^{14}$. Entendemos que o conceito de pessoa pública é um conceito dinâmico. Quem é hoje pessoa pública, pode vir a ser considerado pessoa privada amanhã. $\mathrm{O}$ enquadramento numa ou noutra categoria dependerá, como dissemos anteriormente, da - legítima - expectativa que essas pessoas têm de serem ou não expostas nos e pelos meios de comunicação. Portanto, o interesse público sobre pessoas públicas ou privadas não é perene. Por quê? Porque a condição de públicas dessas pessoas também não é eterna: é circunstancial e, vale reiterar, mutável ${ }^{15}$.

\footnotetext{
${ }^{14}$ Fundamentamos nossa percepção no Código de Ética dos Jornalistas Brasileiros que, em linhas gerais, impõe aos meios de comunicação, bem como aos controladores, operadores e encarregados do tratamento das informações que circulam nestes, que as informações de interesse público (Art. $9^{\circ}$, Código de Ética dos Jornalistas Brasileiros. É dever do jornalista: a) Divulgar todos os fatos que sejam de interesse público) divulgadas tenham por propósito o interesse social e coletivo (Art. $3^{\circ}$, Código de Ética dos Jornalistas Brasileiros. A informação divulgada pelos meios de comunicação pública se pautará pela real ocorrência dos fatos e terá por finalidade o interesse social e coletivo) e, mais do que isso, que tratem os noticiados ou retratados com o devido respeito (Art. 14, Código de Ética dos Jornalistas Brasileiros. O jornalista deve: b) Tratar com respeito a todas as pessoas mencionadas nas informações que divulgar.). Com base nisso, convenhamos, não parece nada respeitoso, tampouco de interesse público ou social, desprezar a intimidade de alguém em prol de interesses econômicos - dos meios de comunicação, que lucrarão com a vendagem desse tipo de informação que será consumida pelos fãs e apreciadores do cantor $\mathrm{Z}$ e da atriz $\mathrm{W}$ - e egoísticos - dos mesmos fãs e curiosos que pouco ou nada se importam com a intimidade desses artistas.

${ }^{15}$ É o que aconteceria, por exemplo, com uma determinada artista famosa que, após atuar anos e anos na TV e no cinema, simplesmente decidisse, por questões pessoais e que digam respeito apenas a ela, sair de cena e ensimesmar-se no anonimato de uma vida não mais pública. Não é porque um dia foi pessoa pública que deverá sê-la para sempre. Sua característica de pessoa pública é condição dinâmica e que, justamente por isto, pode se alterar ao longo tempo, a fim de que essa atriz outrora famosa deva agora ser vista - e tratada pelos meios de comunicação - como pessoa privada. Advirto, contudo, que estas minhas conclusões têm a ver com os aspectos extrapatrimoniais decorrentes das noções de pessoa pública e de pessoa privada. É que, caso estejamos falando de questões de índole patrimonial - como, v.g., o fato dessa atriz desejar que suas novelas e filmes não sejam mais exibidos ou reexibidos - será preciso analisar a questão sobre a ótica das externalidades que, enquanto falhas de mercado que são, comprometeriam a eficiência do contrato e de uma solução que indicasse a aplicação pura do direito ao esquecimento. É que, nesse caso, me parece que o custo social da não (re)exibição das atrações televisivas ou cinematográficas superaria - em muito - o benefício desta retirada de conteúdo. Assim, tendo em vista que quem deveria internalizar essa externalidade deveria ser aquele que promove essa internalização com o menor custo possível, caberia à atriz desligar a TV ou não ver seus filmes porque essa seria uma solução menos gravosa - e, pois, menos onerosa - do que tolher a sociedade e os demais atores e atrizes - que têm interesses extrapatrimoniais e patrimoniais em jogo.
}

Enfim, explicadas algumas das regras que auxiliam na justificação da nossa fórmula do direito ao esquecimento, tentemos aplica-la ao recente e triste caso da morte de uma Vereadora a tiros que gerou, além de comoção, a propagação de inadmissíveis desrespeitos à sua memória. 


\subsubsection{A $3^{a}$ Regra (Critério da Novidade): Além de olharmos para a pessoa retratada e para a natureza do conteúdo do que se informa, devemos aferir a atualidade dessa informação}

O terceiro passo para que definamos os níveis de relevância de uma dada informação consiste em aferir sua novidade - ou atualidade: trata-se de matéria atual ou antiga? O conteúdo é inédito ou requentado? É uma news propriamente dita ou uma reheated news?

Esse tipo de questionamento nos ajudaria inicialmente a distinguir situações de relevância 4-5 (quatro-cinco) ou 1-2 (um-dois), de modo que o que as diferenciaria seria a atualidade ou a antiguidade de reportagens, matérias, publicações, imagens e demais conteúdos que, à título de informação, se propagam pelos meios de comunicação. O outro propósito da utilização desse critério é o de auxiliar na identificação, tanto quanto possível, da (in)existência da predominância do caráter informativo em determinada publicação. É bem verdade que este não será o único parâmetro apto para que se distinga quando as liberdades comunicativas têm caráter secundário, mas certamente o critério da atualidade/novidade será um importante aliado para que consigamos perceber esta diferenciação.

Publicações antigas ou notícias requentadas tenderão a uma classificação em níveis inferiores de relevância da informação, tendo em vista que, por já terem cumprido o objetivo de informar no passado, se divorciarão, a priori, do cumprimento das liberdades comunicativas ao serem (re)publicadas com o provável intuito lucrativo - ou de influenciar interlocutores - disfarçado de um interesse informativo que é meramente secundário. Nessas hipóteses- em que a informação propriamente dita fica em segundo plano -, o direito ao esquecimento deveria, a meu sentir, ser aplicado, ainda que tal se desse - ao menos - para que se garantisse um direito de resposta ou de errata ou uma indenização em favor de quem se considerar, em razão dessas reheated news, vítima dos meios de comunicação.

\section{CONCLUSÃO}

Finalmente, com base nas regras que aqui delineamos, esperamos ter conseguido produzir um manual de instruções sobre a aplicação do direito ao 
esquecimento.

Pelo que até aqui expusemos, seria possível criar categorias de (ir)relevância da informação em três possíveis estratos de importância, a saber: 1) informações relevantes (as quais corresponderiam aos níveis quatro e cinco de relevância); 2) informações mais ou menos relevantes (que seriam concernentes ao nível três de relevância) e; finalmente, 3) informações irrelevantes (nas quais se inseririam as informações de nível um e dois de relevância).

Com efeito, quando as variáveis de uma informação são todas públicas (pessoa pública e informação pública), o nível de relevância dessa informação sempre ficará entre os graus 4 (quatro) e 5 (cinco), independente da atualidade ou não do conteúdo compartilhado (que servirá de critério para que definamos graus de relevância dessa informação relevante). Logo, informações públicas de pessoas (também) públicas serão sempre relevantes e, com isso, tenderão à não aplicação do direito ao esquecimento. A seu turno, quando todas as variáveis de uma informação são privadas (pessoa privada e informação privada), o nível de relevância da informação sempre ficará entre 1 (um) e 2 (dois), sem que a atualidade ou não desse conteúdo impacte no caráter irrelevante dessa informação. Por conseguinte, informações privadas de pessoas (também) privadas serão sempre irrelevantes, pelo que tenderão, em regra, à aplicação do direito ao esquecimento. Por fim, permanecerão no nível 3 (três) de relevância as informações que, híbridas (público-privadas), ora tenderão à aplicação do dever de esquecimento; ora tenderão à preservação da memória e das liberdades comunicativas.

Em suma, o que queremos dizer é que há 1) informações relevantes demais para serem esquecidas- pelo que, infensas ao direito ao esquecimento, são mais propensas à obrigação moral de um devoir de mémoire-; 2) há informações irrelevantes demais para serem lembradas- e, pois, merecem ser esquecidas se lhes aplicando alguma das oito possíveis facetas do direito ao esquecimento - e; 3) há informações híbridas (público-privadas) que, por serem mais ou menos relevantes, demandarão o necessário sopesamento de valores - ponderação de interesses - in concreto para fins de (in)aplicação do direito ao esquecimento.

O direito ao esquecimento pode ser o pior dos ataques; a mais vil das agressões; a contumélia mais irremissível às liberdades comunicativas. Mas o direito ao esquecimento também pode ser a mais nobre das soluções; a mais digna das 
salvaguardas e; uma das poucas, senão a única, alternativa para coibir os abusos das liberdades de expressão; de crítica e; de opinião que, às vezes, dão mais valor ao verbo denegrir do que ao verbo informar.

\section{REFERENCIAS}

ABRIL, Patricia Sanchez; LIPTON, Jacqueline D..The Right to Be Forgotten: Who Decides What the World Forgets. In Kentucky Law Journal, Vol. 103, Issue 3, 2015. Disponível em: <http://www.kentuckylawjournal.org/wpcontent/uploads/2015/02/103KyLJ363.pdf>. Acesso em: 13.04.2017.

AMBROSE, Meg Leta; AUSLOOS, Jef. The Right to Be Forgotten Across the Pond. In Journal of Information Policy, Vol. 3, 2013. Disponível em: <http://www.jstor.org/stable/10.5325/jinfopoli.3.2013.0001>. Accesso em: 19/06/2017. ALMEIDA JUNIOR, Vitor de Azevedo. A imagem fora de contexto: o uso de imagens de arquivo. In SCHREIBER, Anderson (Coord.). Direito e mídia. São Paulo: Atlas, 2013.

BAZÁN, Victor. Libertad de información y derechos a la honra y a la vida privada : conexiones e interferências. In Revista de Direito do Estado: RDE, n. 11, p. 3-53, jul./set. 2008.

CASTELLS, Manuel. A Era da Informação: economia, sociedade e cultura, 2 v.. Trad. Klauss Brandini Gehardt. São Paulo: Paz e Terra, 2006

COASE, Ronald H. The problem of social cost. The Journal of Law and Economics, v. 3, 1960.

COSTA, André Brandão Nery. Direito ao esquecimento na internet: a scarlet letter digital. In SCHREIBER, Anderson (Coord.). Direito e mídia. São Paulo: Atlas, 2013. GARCIA, Enéas Costa. Responsabilidade civil nos meios de comunicação. São Paulo: Editora Juarez de Oliveira, 2002, p. 234.

GOLDBERG, Erica. Free Speech Consequentialism. In Columbia Law Review, Vol. 116, No. 3, 2016. Disponível em: <http://www.jstor.org/stable/43783393>. Acessoem: $30 / 11 / 2017$.

LETTERON, Roseline. Le droit a l'oubli. Revue du Droit Public et de la Science Politique en France et a L'etranger, n. 2, p. 385-424, mars./avr. 1996.

MENDONÇA, Paulo Roberto Soares. O direito da sociedade à informação jornalística e 
os direitos da pessoa. In Revista de Direito da Procuradoria Geral do Município do Rio de Janeiro, v. 3, n. 3, p. 171-196, 2002.

PORTO, Antônio José Maristrello; GOMES, Lucas Thevenard. Análise econômica da função social dos contratos: críticas e aprofundamentos. In Economic Analysis of Law Review, Brasília, 2010.

POSNER, Richard. A. Economic Analysis of Law. Parte I. Cap. I. New York: Aspen Publishers, 2007.

_. Fronteiras da Teoria do Direito. Editora: WMF Martins Fontes, São Paulo, 2011.

POZEN, David E.. Privacy-Privacy Tradeoffs. In The University of Chicago Law Review, Vol. 83, No. 1, 2016.

SCHWARTZ, Paulo M..The Eu-U.S. Privacy Collision: A Turn to Institutions and Procedures. In Harvard Law Review, Vol. 126, No. 7, 2013. Disponível em:

<http://www.jstor.org/stable/23415063>. Acesso em: 30/11/2017.

SHAVELL, Steven. Foundations of Economic Analysis of Law. Harvard University Press, 2004.

TOURIÑO, Alejandro. El Derecho al Olvido y a la Intimidad en Internet. Madrid:

Catarata, 2014.

ULEN, Thomas; COOTER, Robert. Direito \& Economia. Porto Alegre: Bookman, $5^{\text {a }}$ Ed., 2010. 